\title{
Repensando a circulação
e a adoção de crianças
negras na família brasileira
}

Rethinking the circulation and adoption of black children in the Brazilian family

\section{Vanessa Cristina dos Santos Saraiva*}

\begin{abstract}
Resumo - Esse estudo objetiva realizar uma análise das formas de organização, resistência e proteção adotadas historicamente pelas famílias negras brasileiras diante das ações e determinações do Estado. A partir de análise bibliográfica, retomaremos o conceito de circulação historicamente compreendido pelos operadores do direito como uma prática nociva e prejudicial às crianças, a qual era adotada, sobretudo, por famílias negras e empobrecidas do país. Partimos do pressuposto de que esse era um mecanismo adotado por essas famílias para driblar a possibilidade de institucionalização dos filhos em espaços marcados pela violência, destruição de vínculos familiares, afastamento territorial da comunidade e adoções irregulares. Constatamos que se constitui na atualidade como forma de assegurar os direitos dessas crianças quando permite o acesso à família ampliada e à convivência com família paterna. Palavras-chave: circulação e adoção de crianças; família negra; mulheres negras; resistência; campo sociojurídico.
\end{abstract}

\begin{abstract}
This study aims to analyze the forms of organization, resistance, and protection historically adopted by Brazilian black families in the face of State actions and determinations. From bibliographical analysis, we return to the concept of circulation historically understood by legal operators as a harmful practice and harmful to children, which were adopted, above all, by black and impoverished families of the country. We assumed that this was a mechanism adopted by these families to circumvent the possibility of institutionalization of children in spaces marked by violence, destruction of family ties, territorial separation of the community, and irregular adoptions. We find that it is nowadays a way of guaranteeing the rights of these children when it allows access to the extended and paternal family.

Keywords: circulation and adoption of children; black family; black women; resistance; socio-legal field.
\end{abstract}

\footnotetext{
* Professora substituta na Universidade Federal Rural do Rio de Janeiro em 2018-2019, atuou na Prefeitura Municipal de Duque de Caxias entre 2015-2017 em Abrigo Institucional e Conselho Tutelar. Doutoranda do Programa de Pós Graduação em Serviço Social da Universidade do Estado do Rio de Janeiro (PPGSS/UERJ). Email: vancristinasaraiva@gmail.com. ORCID: https://orcid.org/0000-0002-9515-7910.
} 


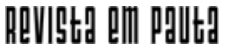

\} REPENSANDO A CIRCULAÇÃO E A ADOÇÃO DE CRIANÇA - SARAIVA, V. C. S. \}

DOI: $10.12957 /$ REP.2020.47216

"É preciso uma aldeia inteira para cuidar de uma criança"

(Provérbio africano)

\section{Introdução}

Esse estudo se trata de revisão bibliográfica fomentada pela imersão da pesquisadora na realidade de crianças e adolescentes negros abrigados em unidades de acolhimento institucional (UA) e que estavam em processo de reintegração familiar ou adoção nas regiões periféricas do Rio de Janeiro. Ao tentar retomar a trajetória dessas crianças e adolescentes, majoritariamente negros, de acordo com o Módulo Criança Adolescente (MCA, 2019), na perspectiva de promover e assegurar direitos, deparo-me com uma realidade em que as famílias negras encontram-se em condição de apartheid social: com dificuldade de acesso ou mesmo não acesso a direitos como moradia, emprego, saúde, escolarização etc. Ou seja, sem apoio estatal para assegurar a convivência familiar e comunitária das crianças, conforme preconiza o Plano Nacional de Convivência Familiar e Comunitária de 2009. Essa normativa, juntamente com a Lei $n^{\circ} 8.069$, de 1990, está orientando esta pesquisa. Pressupomos que as famílias, então, seguem penalizadas e criminalizadas, sem conseguir romper os ciclos de institucionalização pela condição de pobreza extrema em que se encontram.

Além disso, partimos da compreensão de que a situação dessas famílias é marca deixada pela colonização, pelo escravismo, pelo racismo estrutural e institucional. Fenômenos que, de forma interseccional, impõem e recompõem a subalternização, a imobilização social e a desumanização à população negra (MOURA, 1994; NASCIMENTO, 1979; ALMEIDA, 2014).

Assim, é fundamental perceber que tratar o campo da infância e adolescência é tratar de um histórico tensionamento e disputa social. O lugar das crianças na organização familiar sempre esteve atravessado por valores humanitários, cristãos e por sentimentos como compaixão, mas também é marcado por exercer uma função social e política na história da humanidade. A existência de um filho, nesta perspectiva, significa a consumação de um casamento, demarca a virilidade do homem e a capacidade das muIheres em manter o grupo familiar organizado. Isto é, ter uma família e uma criança é ter status social de família bem-sucedida e "estruturada". Nesse sentido, a criança possui um valor e por isso se transforma historicamente em objeto de disputas: econômica, política, simbólica, cultural. Por isso, a circulação de crianças é um fenômeno criticado e interpretado como algo nocivo, haja vista que ter uma criança é sinônimo de ter um lar estruturado, mediado de amor e alegria, tal como nos mostrou Abreu (2002).

A criança é um valor familiar. Logo, não faz sentido afastá-la, retirá-la ou mesmo circular essa criança para além do convívio familiar. Isso é visto como uma heresia. Todavia, tentaremos nesse estudo desconstruir esse pressuposto a partir da revisão bibliográfica das elaborações de Slenes (1988) 


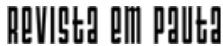

\} REPENSANDO A CIRCULAÇÃO E A ADOÇÃO DE CRIANÇA - SARAIVA, V. C. S. \}

DOI: $10.12957 /$ REP.2020.47216

e Davis (2016), autores que compreendem que as famílias são construções historicamente situadas e que o olhar sobre ela é moderno, eurocêntrico e sofre impactos das relações patriarcais. É uma instância racializada, generificada. Ou seja, qualquer outra forma de constituir família, tal como a família negra se organiza, é vista como negativa, ruim, fora da norma padrão, desestruturada (ABREU, 2002).

Buscamos evidenciar que circular crianças é prática inspirada na tradição africana, asseguradora de direitos e adotada por famílias referenciadas por mulheres negras como forma de resistência. Nessa organização, a criança não é vista como objeto ou mercadoria, mas sim como um filho de todos os integrantes do grupo familiar. Essa é uma alternativa adotada por esses grupos na perspectiva de manutenção da família negra, bem como dos hábitos culturais próprios desses agrupamentos. Uma forma de resistir mediante a desresponsabilização e abandono estatal, negação de direitos e desumanização da vida, sobretudo fomentada pelo apoio do ordenamento/ campo sociojurídico - braço direito do Estado racializado, segundo Almeida (2018) -, o qual preconiza a institucionalização das crianças e a criminalização das mulheres negras.

Demonstraremos também que circulação de crianças é uma proposta que se alinha às normas direcionadas à infância, pois, de acordo com o Estatuto da Criança e do Adolescente, Lei no 8.069, de 1990, é "dever da família, da comunidade, da sociedade em geral e do poder público assegurar, com absoluta prioridade, a efetivação dos direitos" (BRASIL, 1990). Afirmase, dessa maneira, que o cuidado e a responsabilidade com as crianças são coletivos. Por isso, a circulação de crianças deve ser repensada, fortalecida e não criminalizada, tal como tem ocorrido historicamente. Ela tem sido a alternativa adotada pelas famílias empobrecidas e referenciadas por mulheres negras para não terem os filhos acolhidos em espaços institucionalizados.

Em outros termos, é mecanismo de resistência em face da seletividade jurídica em vigência, é forma de retomar a organização familiar a partir dos pressupostos coletivos afrocentrados. Repensar essa prática é repensar o paradigma do cuidado para a criança na organização da família e compreender que a responsabilidade no cuidado é de todos, não somente da mulher. É, portanto, repensar as formas como têm se constituído as políticas sociais direcionadas à infância e às famílias no Brasil, as quais têm balizado ações com práticas racistas, seletivas, pautadas nas generificações e criminalizações, sobretudo na figura da mulher negra. Assim, é tarefa urgente a ser realizada.

\section{Famílias negras, circulação de crianças e resistência}

Trabalhar o conceito de circulação no âmbito das famílias brasileiras na atualidade é problematizar e analisar a realidade de crianças e 


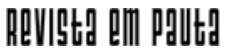

\} REPENSANDO A CIRCULAÇÃO E A ADOÇÃO DE CRIANÇA - SARAIVA, V. C. S. \}

DOI: $10.12957 /$ REP.2020.47216

adolescentes, bem como dos mecanismos incorporados historicamente (desde o período pós-abolição) pelas famílias negras e empobrecidas para sobreviver e assegurar, de alguma maneira, o não rompimento dos laços afetivos na conjuntura histórica marcada pelo racismo e pela desigualdade social. Quando Pires e Gill (2017) asseguram que nem todas as crianças vingam, as autoras estão afirmando que historicamente na sociedade brasileira foram constituídas formas de doutrinar e organizar, com mediação do Estado e do aparato jurídico, a dinâmica dessas famílias a partir da compreensão de que as famílias negras são "degeneradas, promíscuas e descuidadas".

As mulheres negras historicamente foram vistas apenas como procriadoras, nos termos de Davis (2016); eram enxergadas unicamente como fazedoras de nascimentos "breeders", em oposição ao papel de "mães". "As crianças podiam ser vendidas para longe delas como se vendiam as crias de animais (DAVIS, 2016, p. 15)". Entretanto, a forma com que essas mulheres eram vistas não se modificou. Ao contrário, com o passar dos anos foi reformulada; agora, essas mulheres negras e mães são vistas como aquelas que podem contribuir para o insucesso, o adoecimento e, em último caso, para a morte de seus filhos. Por isso, demandam constante monitoramento por parte do Estado a partir de uma lógica de desumanização e compreensão de que estas são negligentes (SLENES, 1988; OLIVEIRA, 2016; COSTA, 1979; DAVIS, 2016).

A negligência é caracterizada pela falta de cuidado e desleixo proposital em determinada situação e tem sido adotada para justificar os recolhimentos em abrigos de crianças e adolescentes negros (MCA, 2019). Contudo, é preciso compreender que esse processo tem vinculação direta com o racismo, haja vista que as famílias caracterizadas como negligentes são extremamente pobres, não conseguindo realizar cuidados com os filhos a partir das diretrizes estatais. Isso é resultado do processo de colonização, do racismo estrutural e institucional, do pacto democrático racial ${ }^{1}$, da não integração social e econômica da população negra no pós-abolição, do genocídio e de ações implementadas por um Estado racializado e seletivo, baseado no necropoder (MOURA, 1994; NASCIMENTO, 1979; MBEMBE, 2018).

Almeida afirma (2014, p. 131) que "o racismo e o sexismo atuam definindo para homens e mulheres negras lugares desprivilegiados na sociedade, quase intransponíveis". Livramento (2012), por sua vez, demonstra como o Estado se constituiu como aparato importante na reprodução de uma ideal de família incapaz, descuidada e que precisa continuamente de monitoramento e orientação de instâncias estatais e jurídicas para viver de forma aceitável pela sociedade. Esses grupos familiares analisados são majoritariamente empobrecidos e chefiados por mulheres negras. Tal fato nos

\footnotetext{
1 Para Guimarães (1999) ocorreu no Brasil a disseminação de uma harmonia entre os negros, brancos e indígenas na construção da nação. Nega-se, dessa forma, que houvesse aqui qualquer tipo de racismo ou tratamentos baseados nas hierarquizações raciais, pois "somos um povo somente".
} 


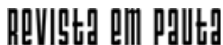

\} REPENSANDO A CIRCULAÇÃO E A ADOÇÃO DE CRIANÇA - SARAIVA, V. C. S. \}

DOI: $10.12957 /$ REP.2020.47216

auxilia a compreender de que maneira a colonialidade do poder se reatualiza e se refuncionaliza na (re)produção das relações sociais. Os lugares das famílias negras são recompostos de forma subalterna: a casa grande e a senzala, as famílias brancas e as famílias negras, os ricos e os pobres, as crianças e os menores, os abandonados, os desvalidos, os em situação de rua.

Embora o discurso seja de uma igualdade jurídica, essa perspectiva binária persiste, se expressando nos órgãos e instituições que atendem essa família negra e demonstra a sociedade patriarcal, racista, desigual, penalizadora e que reatualiza as formas de dominação e doutrinação das famílias negras brasileiras. A justificativa é o controle do trabalho, a manutenção da ordem familiar, os direitos das crianças e dos adolescentes. Contudo, buscase preservar a manutenção das taxas de lucratividade do modelo capitalista de produção, tendo o racismo como potencializador desse processo, haja vista que, segundo Almeida (2014), o racismo é funcional ao ordenamento capitalista.

Diante disso, é preciso desconstruir os mitos que envolvem a dinâmica das famílias negras. Essa visão de incapacidade de construir laços afetivos familiares e de realizar cuidados com os filhos tem vinculação direta com a falsa ideia difundida de que as famílias negras não existiram. A família negra, para Slenes (1988), não era forma organizativa incomum, tal como é divulgado, mas sim um mecanismo fundamental de dominação adotado no período do escravismo. Esse aburguesamento junto aos segmentos escravizados foi imposto a partir do primado colonial eurocêntrico, tendo em vista o interesse em controlar o processo de trabalho. Na medida em que o escravizado constitui família, surge um motivo (esposa e filhos) importante a ser usado pelo senhor para impedir fugas, tensionar cada vez mais o uso dessa força de trabalho e impor uma "humanização ao ser movente animalizado e violento" ou humanizar as unidades de trabalho lucrativas (SLENES, 1988 p.195).

Esses mecanismos de dominação e controle se refuncionalizaram e se perpetuaram no decorrer da história brasileira. Isso fez com que as famílias adotassem historicamente formas de resistir a essa dominação posta. No decorrer da era do menorismo ${ }^{2}$, por exemplo, criaram novos arranjos e dinâmicas de convívio familiar, na tentativa de proteger e garantir a convivência das crianças nos grupos familiares consanguíneos/família extensa, evitando a institucionalização e as adoções ilegais de suas crianças.

Fonseca (1995) denomina esse fenômeno como circulação de crianças, movimento histórico, não limitado à realidade brasileira, que explica o momento em que crianças passam parte da infância ou juventude em casas que não a de seus genitores. Tudo isso devido à dinâmica financeira do grupo familiar e à sua necessidade de reorganização, tendo em vista a

${ }^{2}$ Período em que estavam em vigência os códigos de menores de 1927 e 1979, que monitoravam e controlavam, de forma violenta, a infância pobre e suas famílias "negligentes". Nesse período a política direcionada à infância preconizava os acolhimentos massivos nos abrigos. 


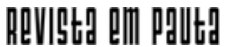

\} REPENSANDO A CIRCULAÇÃO E A ADOÇÃO DE CRIANÇA - SARAIVA, V. C. S. \}

DOI: $10.12957 /$ REP.2020.47216

dissolução da relação dos pais e as migrações, por exemplo. Ou seja, são motivos diversos que conduzem os grupos a repensarem o lugar em que as crianças e os adolescentes passarão a habitar. Ocorre, portanto, a transferência de uma criança entre uma família e outra, que pode ou não pressupor a materialização sob a forma de guarda temporária ou de adoção propriamente dita.

Abreu (2002) afirma que a circulação de crianças é uma prática naturalizada no Brasil, porém, é percebida pelo autor como mecanismo de negligência, perpassado por uma relação de poder e interesse econômico entre os atores envolvidos nesse processo. A crítica consiste no fato de que a circulação de crianças seria uma forma de fomentar as adoções ilegais, quer dizer, a mercantilização da criança, a qual permanece objetificada. Além disso, é prática perpassada por disputas familiares marcadas pelas relações patriarcais, que colocavam as mães dessas crianças em lugar de subalternidade e sem poder decisório sobre o futuro dos filhos. Contudo, nosso argumento é de que, no âmbito das famílias negras, essa é uma estratégia de sobrevivência e de manutenção do grupo familiar.

Fonseca (2002), na obra Mãe é uma só?, ressalta que ocorreu uma construção epistemológica, a qual busca criticar negativamente as formas organizativas de grupos sociais que não se adequam ao imperativo posto pela normatividade eurocêntrica. Por isso, são tidos como epistemologias não ocidentais, inadequadas a essa realidade. Nesse movimento, ocorre uma negação das particularidades e uma folclorização do diferente, conduzindo os sujeitos a interpretar determinados hábitos culturais, tais como a circulação de crianças, como algo negativo.

No entanto, em uma realidade como a brasileira, onde não ocorrem facilmente as desistintucionalizações das $\mathrm{UAs}^{3}$, pois o Estado não oferece suporte econômico e social para essas famílias, essa é uma prática importante para as famílias, pois, de fato, ocorre a criminalização das mulheres e institucionalização dos seus filhos ${ }^{4}$. Organizar-se a partir da circulação foi o mecanismo que essas famílias negras adotaram para assegurar os cuidados dos filhos em espaços perpassados por afeto, mesmo que essa forma do cuidado com os descendentes do grupo familiar não esteja alinhada aos padrões normativos. Morar com uma tia, madrinha, avó, ou seja, a circulação de crianças, permite o aumento de filiação na medida em que a criança passa a conviver com diferentes sujeitos maternos e paternos e que integram o seu grupo familiar originário. É prática menos violenta e desumanizadora, se compararmos aos recolhimentos realizados às $U \mathrm{As}^{5}$ hoje.

\footnotetext{
${ }^{3}$ De acordo com o Conselho Nacional de Crianças Acolhidas (CNCA, 2019), existem 47 mil crianças institucionalizadas.

${ }^{4} 67 \%$ das crianças abrigadas no Brasil são pretas ou pardas, de acordo com Conselho Nacional de Justiça.

${ }^{5}$ Essas unidades, antes do reordenamento proposto pela Lei n. 8.069, de 1990, eram denominadas como Fundação Nacional do Bem-Estar do Menor (FUNABEM) e Fundação Estadual do Bem-Estar do Menor (FEBEM) (SARAIVA, 2018).
} 


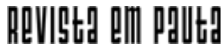

\} REPENSANDO A CIRCULAÇÃO E A ADOÇÃO DE CRIANÇA - SARAIVA, V. C. S. \}

DOI: $10.12957 /$ REP.2020.47216

Essas unidades, mesmo sendo reordenadas com o ECA, não conseguem romper efetivamente com as ações violadoras próprias da era da menoridade. A história da construção da proteção social direcionada à infância no Brasil (ALTOÉ, 2008) é mediada por ações violentas, destruição dos vínculos familiares, afastamento do convívio comunitário e danos psicológicos ao acolhido. Marcas inapagáveis que ainda se perpetuam em nossa realidade.

Outro fator que tensiona esse movimento de circulação de crianças é a fuga dos processos de destituição parcial ou total do poder familiar ${ }^{6}$, prática comum desde a era do menorismo. É o momento jurídico em que são retirados os direitos das famílias sobre as crianças. De acordo com a Constituição Federal de 1988, o poder familiar é um "complexo de direitos e deveres quanto à pessoa e bens do filho, exercidos pelos pais na mais estreita colaboração, e em igualdade de condições" (BRASIL, 1988). Desse modo, podemos afirmar que a lei postula uma possível igualdade de direitos e obrigações entre homens e mulheres no que tange ao cuidado com os filhos.

Todavia, os dados da realidade evidenciam que essa responsabilização está direcionada majoritariamente às mulheres. Os números sobre registro civil produzidos pela Corregedoria-Geral da Justiça do Rio de Janeiro de 2018 informam que, no Brasil, 4.869.363 de crianças e adolescentes não possuem informação sobre o nome do pai nas certidões de nascimento. No estado do Rio de Janeiro, esses índices representam 7\%. Não encontramos dados referentes às destituições do poder familiar; contudo, as mulheres são identificadas como a referência familiar no sustento do grupo, no convívio e nos cuidados com os filhos, por isso são as enquadradas como violadoras e negligenciadoras do cuidado, haja vista que a figura paterna não é presente nesses grupos familiares (CONJUR, 2019).

A pobreza é marca comum entre essas famílias. Segundo o Ipea (2011), 21,7 milhões de famílias são chefiadas por mulheres, e 69\%, por mulheres negras. Esse fato não é motivo para a destituição do poder familiar, mas é recorrentemente confundido pelos operadores do sistema de garantia de direitos como negligência (em segundo lugar nos motivos do acolhimento institucional, segundo Saraiva - 2017). Cabe ressaltar que todos os profissionais que atuam nos eixos defesa, promoção, controle e efetivação dos direitos da criança e do adolescente nas diferentes instituições, órgãos públicos ou privados, e integrantes da sociedade civil são denominados operadores do sistema de garantia de direitos. Esses profissionais são advogados, assistentes sociais, psicólogos, gestores, juízes, promotores, defensores públicos e conselheiros tutelares, de acordo com a Resolução $n^{\circ} 113$, do Conselho Nacional dos Direitos da Criança e do Adolescente (CONANDA).

Varikas (2014), ao tratar dos questionamentos realizados por homens brancos contra uma mulher negra sobre a sua capacidade intelectual,

\footnotetext{
${ }^{6}$ Anteriormente denominados como perda do pátrio poder, de acordo com o Código Civil de 1916.
} 


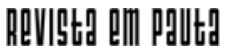

\} REPENSANDO A CIRCULAÇÃO E A ADOÇÃO DE CRIANÇA - SARAIVA, V. C. S. \}

DOI: $10.12957 /$ REP.2020.47216

nos fornece elementos para evidenciar que a mulher negra sempre está sendo testada a partir de uma lógica de desumanização, inferiorização, animalização, criminalização e hipersexualização. Tudo isso devido à hierarquização de raças e de gênero disseminada mundialmente pelo saber eurocentrado, o qual afirma que a figura do negro e da mulher são bestializados, ou seja, incapazes de exercer qualquer atividade intelectiva.

Essa ideia nos auxilia a pensar na relação estabelecida entre a esfera jurídica e as famílias chefiadas por mulheres negras, haja vista que são os mesmos questionamentos realizados hoje: ela possui capacidade para cuidar dessas crianças? Ela realmente ama os filhos? Ela passa o dia todo trabalhando? Isso tudo ocorre sem que se relacione estes dados com a desigualdade social, a exclusão, a inacessibilidade a políticas públicas e o racismo estrutural, que define essas mulheres como impróprias para o cuidado dos filhos. "É exigido responsabilidade das famílias, sem que se perceba que elas próprias estão sofrendo negligência (LIVRAMENTO, 2012, p. 4).

Nesse sentido, é fundamental perceber que a circulação é uma prática adotada pelas famílias negras mais empobrecidas do país. É a estratégia que a mãe sem o suporte do pai biológico da criança e do Estado adotou a fim de não perder esse filho para a institucionalização ou adoção. Em outros termos, podemos afirmar que é resistência histórica desses grupos aos quais foi negado o direito de se organizar em família a partir dos seus próprios hábitos e valores culturais.

De tudo, é fundamental ressaltar que não desejamos aqui negar o caráter violador da ideia de família ${ }^{7}$, nem tampouco romantizar as relações, mas sim afirmar o quanto a produção de uma família negligente serve como vetor justificador de destituições de poder familiar, criminalização das mães negras, acolhimentos, adoções e institucionalizações para um determinado perfil de família: negra e pobre.

\section{A família e a mulher negra como objetos do campo sociojurídico: tensões e desafios}

A família e a mulher têm sido consideradas objetos de análise e intervenção do campo sociojurídico por décadas. Miguens (2019), nos seus estudos, afirma que especialmente no caso da mulher a origem dessa análise data da era medieval ${ }^{8}$. No Brasil, a Constituição de 1988 formalizou algumas das modificações que repercutem sobre a organização familiar e a situação

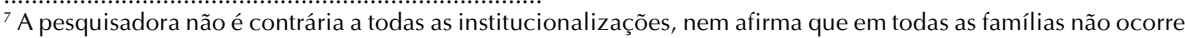
violência contra crianças e adolescentes. Apenas ressalta que é necessário repensar algumas ações e institucionalizações desnecessárias por motivos que poderiam ser resolvidos na rede socioassistencial, como vacinação, encaminhamentos para rede de saúde, orientações sobre o cuidado, responsabilidade paterna etc.

${ }^{8} \mathrm{~A}$ autora afirma que a prática persecutória à figura feminina ainda é internalizada e reproduzida na atualidade pelos operadores do direito, embora alguns avanços jurídicos legais tenham se materializado com o decorrer dos anos.
} 


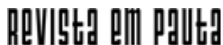

\} REPENSANDO A CIRCULAÇÃO E A ADOÇÃO DE CRIANÇA - SARAIVA, V. C. S. \}

DOI: $10.12957 /$ REP.2020.47216

da mulher. O art. 226 da Carta Magna "liberta", teórica e juridicamente, a mulher da dependência do homem, preconizando que o Estado deve assegurar a proteção dos grupos familiares, mas ainda mantém uma visão muito limitada da família, haja vista que "§ $3^{\circ}$ Para efeito da proteção do Estado, é reconhecida a união estável entre o homem e a mulher como entidade familiar, devendo a lei facilitar sua conversão em casamento" (BRASIL, 1988).

Ademais, não ocorre o reconhecimento de famílias construídas por pessoas do mesmo sexo ou aquelas que fogem à composição casal e filhos. Ou seja, desconsideram-se os variados grupos familiares: a família brasileira. Mesmo assim, leis e normativas foram se conformando ${ }^{9}$ para atender às demandas das famílias, contudo, a construção dessas leis é perpassada por contínuo tensionamento, disputas e interesses de diferentes atores sociais.

Apesar disso, todas essas normas preconizam a centralidade da família para a formulação de políticas públicas. Logo, se a família real não está alinhada às determinações e orientações postas nessas leis, ela passa a ser criminalizada. Essas leis interferem na esfera privada da vida dos sujeitos, podendo restringir a proteção a partir de uma lógica de responsabilização e moralização ao avaliar que os cuidados são exclusivamente dos grupos familiares idealizados. Essa perspectiva é recorrente em espaços do campo sociojurídico que atuam com demandas de famílias, crianças e adolescentes (COSTA, 1979; GOIS; OLIVEIRA, 2019).

Por isso, segundo Gois e Oliveira (2019, p. 69), as situações que chegam à justiça "exigem análises de um conjunto de fatores que não se restringe ao momento atual daquela família", tendo em vista a complexidade que ultrapassa a abrangência das leis. O desafio profissional da categoria de assistentes sociais está posto, pois requer o desvelamento da situação judicializada. Ademais, importa situar a família nesse atual momento histórico, perpassado por relações racializadas e generificadas, cuja equação comum é a pobreza, o apartheid de direitos, a criminalização das famílias e dessas mulheres.

O desafio consiste em enfrentar as assertivas que se coloquem na contramão desse entendimento, pois elas se alinham a uma lógica de violação de direitos, responsabilização e culpabilização das famílias, bem como desresponsabilização do Estado seletivo ${ }^{10}$, racializado e generificado. Para hooks (2015, p. 13) "é construído um mito em que essas mulheres negras são raivosas, que elas acreditam ser incapazes de um discurso racional, incapazes de cuidar dos filhos ou manter a organização familiar". Nesse sentido, Werneck (2010) busca evidenciar como as mulheres negras são vistas e represen-

\footnotetext{
${ }_{9}^{9}$ A título de exemplo, temos a Política Nacional de Assistência Social (PNAS), o Estatuto da Criança e do Adolescente (ECA), O Estatuto da Juventude e o Estatuto do Idoso.

${ }^{10}$ É destacado pelas autoras Gois e Oliveira (2019) o lugar da mulher na proteção das famílias. Essas mulheres exercem atividades laborativas insalubres, por baixos salários e por longas horas de trabalho (como é o caso das trabalhadoras domésticas), mas que passam a ter a relação de cuidados estabelecida com os filhos questionada, interpretadas como fora da conduta normativa, judicializadas e continuamente monitoradas.
} 


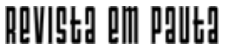

\} REPENSANDO A CIRCULAÇÃO E A ADOÇÃO DE CRIANÇA - SARAIVA, V. C. S. \}

DOI: $10.12957 /$ REP.2020.47216

tadas historicamente a partir do desenvolvimento das categorias escravidão, expropriação colonial, modernidade racializada e dominação eurocêntrica.

Esse lugar é imposto pelo racismo à mulher negra e produzido pelo olhar branco. A mulher passa a ser vista, pelo senso comum, apenas como a mulata sambista, a mulher sexualizada, aquela que não cuida dos filhos. Assim, as situações que os grupos familiares referenciados por mulheres negras demandam no cotidiano do campo sociojurídico devem ser problematizadas criticamente e situadas historicamente a partir destas determinações: raça, gênero e patriarcado.

É necessário evidenciar que todas essas demandas judicializadas são reflexo de uma conjuntura política e social em que a extrema direita lidera em diferentes estados brasileiros. Uma realidade em que se cogita "mandar um míssil e explodir aquelas pessoas" (WITZEL, 2019, Jornal O Globo online), como afirmou o atual governador do Rio de Janeiro ao se referir às famílias empobrecidas, afirmando que esta é a sua proposta de intervenção política nesses espaços. Nesse sentido, incorporar a esse debate os determinantes de raça e gênero é fundamental para repensar formas de ação em diferentes espaços sociocupacionais, sobretudo o campo sociojurídico, uma vez que esse tipo de abordagem pautada na violência e alijamento de direitos é direcionada a um determinado tipo de família: negra, empobrecida, inserida em espaços periféricos e chefiada por mulheres.

Assim, infere-se que ocorre um descompasso entre a mudança de mentalidade dos grupos sociais, as formas de interação das famílias e a construção e aplicação de leis pela justiça. Em outros termos, a construção das leis e normativas que perpassam a realidade das famílias e de mulheres negras é baseada em relações racializadas e generificadas, ou seja, mediadas pelo racismo, machismo e preconceito. As mudanças legais não propõem alterações que transformem o quadro de exclusão, tampouco as políticas de governo. Diante disso, penalizar famílias negras, sobretudo pelas formas culturais em realizar cuidados com os filhos, não situando essas formas de agir com a realidade social, pode sim ser enquadrado como infração ética ao pensarmos na categoria de assistentes sociais. Isso porque "[...] respeitar democraticamente as decisões dos/as usuários/as, mesmo que sejam contrárias aos valores e às crenças individuais dos/as profissionais [...]", é um dever profissional assegurado no Código de Ética dos Assistentes Sociais (CFESS, 1993, p. 26).

Colocar-se a favor da adoção nacional e internacional como única solução, tal como difundem alguns dos operadores do direito, é um grande problema, um desserviço. Dessa maneira, é necessário debater os limites e as soluções propostas pelo ordenamento jurídico diante da situação de crianças que não podem ser reintegradas à família extensa por temor da circulação nos grupos familiares a partir de uma possível incapacidade, mas que também não podem permanecer em acolhimento institucional indefinidamente. Essa solução não inclui a família, tampouco a mãe dessas crianças. Além disso, 


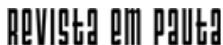

\} REPENSANDO A CIRCULAÇÃO E A ADOÇÃO DE CRIANÇA - SARAIVA, V. C. S. \}

DOI: $10.12957 /$ REP.2020.47216

a perspectiva de fortalecer essa família, tal como preconiza o Plano Nacional de Convivência Familiar e Comunitário (2009), é cotidianamente impactada pela expropriação dos direitos, disputas políticas, manutenção das taxas de lucratividade, racismo, sexismo etc.

A inserção da criança e do adolescente em família substituta é medida excepcional, de acordo com o ECA (BRASIL, 1990), no art. 19, somente podendo ser adotada após inúmeras tentativas dos operadores do sistema de garantia de direitos de trabalhar com o grupo familiar e mediar a ação do Estado no que tange à viabilização de trabalho, moradia, saúde, educação etc. Contudo, a busca por uma família substituta ${ }^{11}$ tem sido corriqueiramente adotada, desconsiderando as particularidades das famílias brasileiras, extremamente empobrecidas no que se refere ao cuidado. A perspectiva é a criminalização ou a culpabilização desses grupos pela condição de pauperismo extremo que vivenciam, o qual é compreendido como negligência familiar.

De acordo com Barroco (2005, p. 47), é "uma forma de discriminação, tendo em vista a não aceitação do que não se adequa aos padrões de comportamento estereotipados como 'corretos'". Para Gonzáles (1988), é estratégia adotada pelo campo sociojurídico face ao racismo estrutural, que, ao se reproduzir nas relações sociais, compreende o corpo negro como não objeto do amor e que somente é visto por partes que interessam a esse olhar eurocentrado para satisfazer fantasias sexuais. Logo, como não pode ser amado, esse corpo negro deve ser retirado do convívio. Essa é uma chave interpretativa importante que fomenta as adoções internacionais.

O pressuposto é de que seja realizada a ação de destituição do poder familiar, entendida por Fonseca (2000) como prática danosa, amarga, antipática, construída por vezes com mediação de provas mal elaboradas, sem ouvir as famílias, porém comumente adotada no âmbito jurídico e tida como a cura de todos os males sociais. A justificativa é de que o interesse da criança deve ser garantido e de que a lei seja cumprida. Portanto, essa ação ocorre desconsiderando a importância de as crianças crescerem junto das famílias de origem e os impactos que esse distanciamento provoca na sua subjetividade, como dificuldade de estabelecer vínculos afetivos, tal como salientou Altoé (2008).

Contudo, a adoção é perpassada por inúmeras complexificações e tensionamentos (dádiva, compaixão, obrigação, busca de respeito, direito, disputa), as quais acabam freando ou não esse processo. Mas os traços da nossa formação social, a raça, o gênero, a idade e o histórico familiar, aliados à busca pelo filho idealizado, são alguns exemplos que servem de vetor para nos conduzir a um entendimento de que adotar não é algo automático, mecanizado, e que serviria como uma salvação para essas crianças.

\footnotetext{
11 Para conseguir solucionar esses conflitos postos pela ordem social vigente marcada pelo racismo e pelo patriarcado, e internalizados pelo ordenamento jurídico, a adoção legal internacional é "posta na mesa" como única alternativa para as crianças negras.
} 


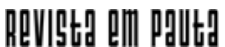

\} REPENSANDO A CIRCULAÇÃO E A ADOÇÃO DE CRIANÇA - SARAIVA, V. C. S. \}

DOI: $10.12957 /$ REP.2020.47216

Em contrapartida, a adoção deve ser questionada por remontar a um movimento próprio da dinâmica escravista: antes sequestrados, agora exilados das famílias de origem. Nesse sentido, deve ser repensada, pois, mesmo no período da escravidão, "a maioria das crianças [...] passava boa parte de seus anos formativos na companhia de seus dois pais. Foi neste contexto, e não em famílias 'quebradas', sem pai presente ou nem mesmo conhecido, que estas crianças foram socializadas" (SLENES, 1988, p. 221).

\section{Considerações finais}

Como ficou evidenciado, a circulação de crianças historicamente foi criminalizada pelo Estado e pelo campo sociojurídico. Todavia, como demonstrou esse estudo, é um mecanismo importante adotado pelas mulheres negras para assegurar a permanência das crianças no mesmo grupo familiar originário, bem como para impedir que essas crianças negras fossem institucionalizadas. Desse modo, a circulação de crianças é uma forma de resistência da família negra brasileira diante das ações do Estado racista.

Isso acontece porque, ao retomarmos os dados da institucionalização no Brasil, verificamos o caráter seletivo, racializado e generificado, sobretudo dos operadores do sistema de garantia de direitos (advogados, assistentes sociais, psicólogos, juízes, promotores e defensores), ao articular ações que serão direcionadas às famílias referenciadas por mulheres negras. Das 47 mil crianças abrigadas, $67 \%$ são pretas e pardas. A maioria das crianças não possui o nome do genitor no registro civil: $7 \%$ somente no Rio de Janeiro (TJRJ, 2015). Se analisarmos a realidade social, verificamos que essas mulheres seguem sem apoio estatal ou estão à mercê de políticas sociais em modalidade básica, com parca efetividade.

A saída adotada pelo poder público não é trabalhar com as famílias na perspectiva de fortalecimento de vínculos familiares e das diretrizes postas no ECA e no Plano Nacional de Convivência Familiar e Comunitária, que se contrapõem à institucionalização e aceitam a adoção como última alternativa. A lógica que se desenvolve é de penalizar, acolher os filhos dessas mulheres e investir na adoção internacional. Assim, adotar uma postura antirracista para repensar a elaboração de laudos e pareceres sociais se coloca como alternativa importante para os profissionais, incluídos as assistentes sociais - no caso deste estudo, focalizam-se as formas como o judiciário tem se relacionado com as famílias negras, em especial, as mulheres (CFESS, 2016). Essa postura profissional nos propõe a construção de uma nova racionalidade antirracista, antipatriarcal e contra a desigualdade.

Nesse sentido, a argumentação realizada compreende a circulação de crianças como lócus privilegiado para o fortalecimento dos vínculos familiares. Além disso, enfrentaria os recolhimentos massivos, gastos públicos com UAs e garantiria o convívio familiar das camadas mais empobrecidas e 


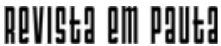

\} REPENSANDO A CIRCULAÇÃO E A ADOÇÃO DE CRIANÇA - SARAIVA, V. C. S. \}

DOI: $10.12957 /$ REP.2020.47216

das famílias negras. Em outros termos, é uma proposta antirracista de compreensão das formas organizativas dos grupos familiares e, assim, se coloca contrariamente à seletividade jurídica na tomada de decisões judiciais. Dessa maneira, deve ser repensada, reavaliada e reinterpretada. Partimos do pressuposto de que o cuidado com crianças demanda uma série de exigências e envolve distintos atores sociais: Estado, sociedade, famílias, homens e muIheres. Portanto, "é preciso uma aldeia inteira para cuidar de uma criança" (provérbio africano)! 


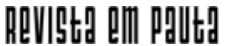

\} REPENSANDO A CIRCULAÇÃO E A ADOÇÃO DE CRIANÇA - SARAIVA, V. C. S. \}

DOI: $10.12957 /$ REP.2020.47216

\section{Referências}

ABREU, D. No bico da cegonha. 2002. Disponível em: http://nuap.etc.br/ content/uploads/2013/06/no_bico_da_cegonha.pdf. Acesso em: 22 abr. 2019.

ALMEIDA, M. S. Desumanização da população negra: genocídio como princípio tácito do capitalismo. Revista Em Pauta: teoria social e realidade contemporânea, n.34, 2014. Disponível em: https://www.e-publicacoes.uerj.br/ index.php/revistaempauta/article/view/15086. Acesso em: 22 abr. 2019.

ALMEIDA, S. O que é racismo estrutural? Belo Horizonte: Letramento, 2018.

ALTOÉ, S. Infâncias perdidas: o cotidiano nos internatos-prisão. 2008. Disponível em: https://static.scielo.org/scielobooks/69ysj/pdf/altoe9788599662946.pdf.Acesso em: 24 set. 2017.

BRASIL. Constituição da República Federativa. Brasília, DF, 1988.

BRASIL. Lei n. 8.069, de 13 de julho de 1990. Dispõe sobre o Estatuto da Criança e do Adolescente e dá outras providências. Diário Oficial da União, Brasília, DF, 16 jul. 1990.

BRASIL. Plano nacional de promoção, proteção e defesa do direito de crianças e adolescentes à convivência familiar e comunitária. Brasília: Secretaria Especial dos Direitos Humanos, 006.

BRASIL. Lei 6697 de 1979. Disponível em: http://www.planalto.gov.br/ ccivil_03/leis/1970-1979/L6697.htm. Acesso em: 23 nov. 2019.

BRASIL. Lei 17943 de 1923. Consolida as leis de assistência e protecção aos menores. Disponível em: http://www.planalto.gov.br/ccivil_03/decreto/ 1910-1929/D17943A.htm. Acesso em: 23 nov. 2019.

BRASIL. Lei 3071 de 1916. Disponível em: http://www.planalto.gov.br/ ccivil_03/LEIS/L3071.htm Acesso em: 23 nov. 2019.

BARROCO, M. L. S. Ética e Serviço Social: fundamentos ontológicos. 3. ed. São Paulo: Cortez, 2005.

CNCA. Cadastro nacional de crianças acolhidas. 2019. Disponível em: http:/ /www.cnj.jus.br/sistemas/infancia-e-juventude/20545-cadastro-nacional-decriancas-acolhidas-cnca. Acesso em: 6 abr. 2017.

CNJ. Cadastro Nacional de Crianças Acolhidas perfil. Disponível em: https:/ /www.cnj.jus.br/cadastro-nacional-de-criancas-acolhidas-cnca/ Acesso em: 6 abr.2017.

CFESS. Código de ética profissional do assistente social. Brasília: CFESS, 1993.

CFESS. Nota técnica"abolicionismo penal"e possibilidade de uma sociedade sem prisões.2016.Disponível em: http://www.cfess.org.br/arquivos/CFESS- 


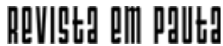

\} REPENSANDO A CIRCULAÇÃO E A ADOÇÃO DE CRIANÇA - SARAIVA, V. C. S. \}

DOI: $10.12957 /$ REP.2020.47216

NotaTecnica-FabioSimasJeffersonLee-AbolicionismoPenal.pdf. Acesso em: 18 jun.2019.

COSTA, J. F. Ordem médica e norma familiar. Rio de Janeiro: Graal, 1979.

CONANDA. Sistema de Garantia dos Direitos da Criança e do Adolescente. Disponível em: http://www.crpsp.org.br/portal/comunicacao/diversos/ mini_cd/pdfs/Res_113_CONANDA.pdf. Acesso em: 22 abr. 2019.

CONJUR-TJRJ. TJ-RJ cria núcleo para reduzir número de crianças sem registro de pai. 2015. Disponível em: https://www.conjur.com.br/2019-fev-02/tj-rjcria-nucleo-reduzir-numero-criancas-registro-pai. Acesso em: 22 abr. 2019.

DAVIS, A. Mulheres, raça e classe. São Paulo: Boitempo, 2016.

FONSECA, C. Da circulação de crianças à adoção internacional: questões de pertencimento e posse.2006. Disponível em: http://www.scielo.br/pdf/ \%0D/cpa/n26/30384.pdf. Acesso em: 8 maio 2019.

FONSECA, C. Mãe é uma só? reflexões em torno de alguns casos brasileiros. 2002. Disponível em: http://www.scielo.br/scielo.php?pid=S010365642002000200005\&script=sci_abstract\&tlng=pt.Acesso em: 8 mar. 2019.

GOIS, D. A.; OLIVEIRA, R. C. S. Famílias uma abordagem social.In:Serviço Social na Justiça de Família. São Paulo: Cortez, 2019.

GONZÁLES, L. A categoria político-cultural de Amefricanidade. Rio de Janeiro: Tempo Brasileiro, 1988.

GUIMARÃES, A; S. A. Racismo e anti-racismo no Brasil. Disponível em: https://edisciplinas.usp.br/pluginfile.php/4116181/mod_resource/content/0/ A. $\% 20$ S.\%20Guimar\%C3\%A3es\%20-\%20Racismo\%20e\%20anti-racismo \%20no\%20Brasil.pdf. Acesso em: 8 mar. 2019.

HOOKS, B. Mulheres negras: moldando a teoria feminista. Revista Brasileira de Ciência Política, Brasília, n. 16, 2015.

IPEA. Retrato das desigualdades de gênero e raça. 2011. Disponível em: http://www.ipea.gov.br/retrato/edicoes_anteriores.html. Acesso em: 27 maio 2019.

LIVRAMENTO, A. M. do et al.A produção de famílias negligentes: analisando processos de destituição do poder familiar. 2012. Disponível em: http://periodicos.ufes.br/argumentum/article/view/2938. Acesso em: 27 maio 2019.

MCA. O que é o MCA e qual o seu objetivo? 2019. Disponível em: http:// mca.mp.rj.gov.br/sobre-o-mca/apresentacao/. Acesso em: 18 maio 2019.

MIGUENS, M.A mulher e o sistema punitivo. In: Direitos e gênero: sistema de proteção. Rio de Janeiro: Grupo Multifoco, 2019.

MOURA, C. Dialética radical do Brasil negro. Anita Garbibaldi. 1994.

MBEMBE, A. Necropolítica. N1 edições, 2018. 


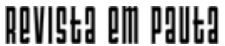

\} REPENSANDO A CIRCULAÇÃO E A ADOÇÃO DE CRIANÇA - SARAIVA, V. C. S. \}

DOI: $10.12957 /$ REP.2020.47216

NASCIMENTO, A. O Genocídio do negro brasileiro: processo de um Racismo Mascarado. São Paulo, Perspectivas, 1979.

OLIVEIRA, L. C. de. Famílias negras centenárias: memórias e narrativas. Rio de Janeiro: Mar de Ideias Navegação Cultural, 2016.

O GLOBO. Witzel causa polêmica ao falar em 'mandar míssil' para explodir traficantes na Cidade de Deus. Rio de Janeiro, 14 de jun. de 2019. Disponível em: https://oglobo.globo.com/rio/witzel-causa-polemica-ao-falar-emmandar-missil-para-explodir-traficantes-na-cidade-de-deus-23741965. Acesso em: 14 jun. 2019.

PIRES, T.;GILL, A."Nem todas as crianças vingam".2017. Disponível em: https://emporiododireito.com.br/leitura/nem-todas-as-criancas-vingam-porthula-pires-e-andrea-gill. Acesso em: 18 maio 2019.

SARAIVA, V. C. dos S. O acolhimento institucional como limitador do acesso aos direitos de crianças e adolescentes do município de Duque de Caxias. Trabalho de Conclusão de Curso (Especialização em Políticas Públicas e Intersetorialidade) - Instituto Federal Fluminense, 2017.

SLENES, R. W. Lares negros, olhares brancos: histórias da família escrava no século XIX. Disponível em: file://C:/Users/user/Downloads/roberts lenes.pdf.Acesso em: 22 abr. 2019.

SLENES, R. W.; FARIA,S. de C. Família escrava e trabalho.Disponível em: http://www.historia.uff.br/tempo/artigos_dossie/artg6-4.pdf. Acesso em: 16 abr. 2019.

VARIKAS, E. Uma negra pode ser poeta?A cor da humanidade. In: A escória do mundo: figuras do pária.São Paulo: Unesp, 2014.

WERNECK, J. Nossos passos vem de longe: Movimentos de mulheres negras e estratégias políticas contra o sexismo e o racismo Disponível em: file:///C:/ Users/user/Downloads/iheid-6316.pdf. Acesso em: 16 abr. 2019.

DOI: $10.12957 /$ rep.2020.47216

Recebido em 05 de julho de 2019.

Aprovado para publicação em 19 de setembro de 2019.

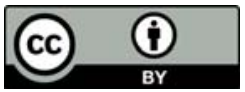

A Revista Em Pauta: Teoria Social e Realidade Contemporânea está licenciada com uma Licença Creative Commons Atribuição 4.0 Internacional. 